This item was submitted to Loughborough's Research Repository by the author.

Items in Figshare are protected by copyright, with all rights reserved, unless otherwise indicated.

\title{
Case based reasoning approach for transaction outcomes prediction on currency markets
}

PLEASE CITE THE PUBLISHED VERSION

PUBLISHER

(c) IEEE

VERSION

VoR (Version of Record)

LICENCE

CC BY-NC-ND 4.0

\section{REPOSITORY RECORD}

Wang, Xiaoming, Martin D. Sykora, Robert Archer, David J. Parish, and Helmut E. Bez. 2019. "Case Based Reasoning Approach for Transaction Outcomes Prediction on Currency Markets". figshare. https://hdl.handle.net/2134/5885. 
This item was submitted to Loughborough's Institutional Repository (https://dspace.lboro.ac.uk/) by the author and is made available under the following Creative Commons Licence conditions.

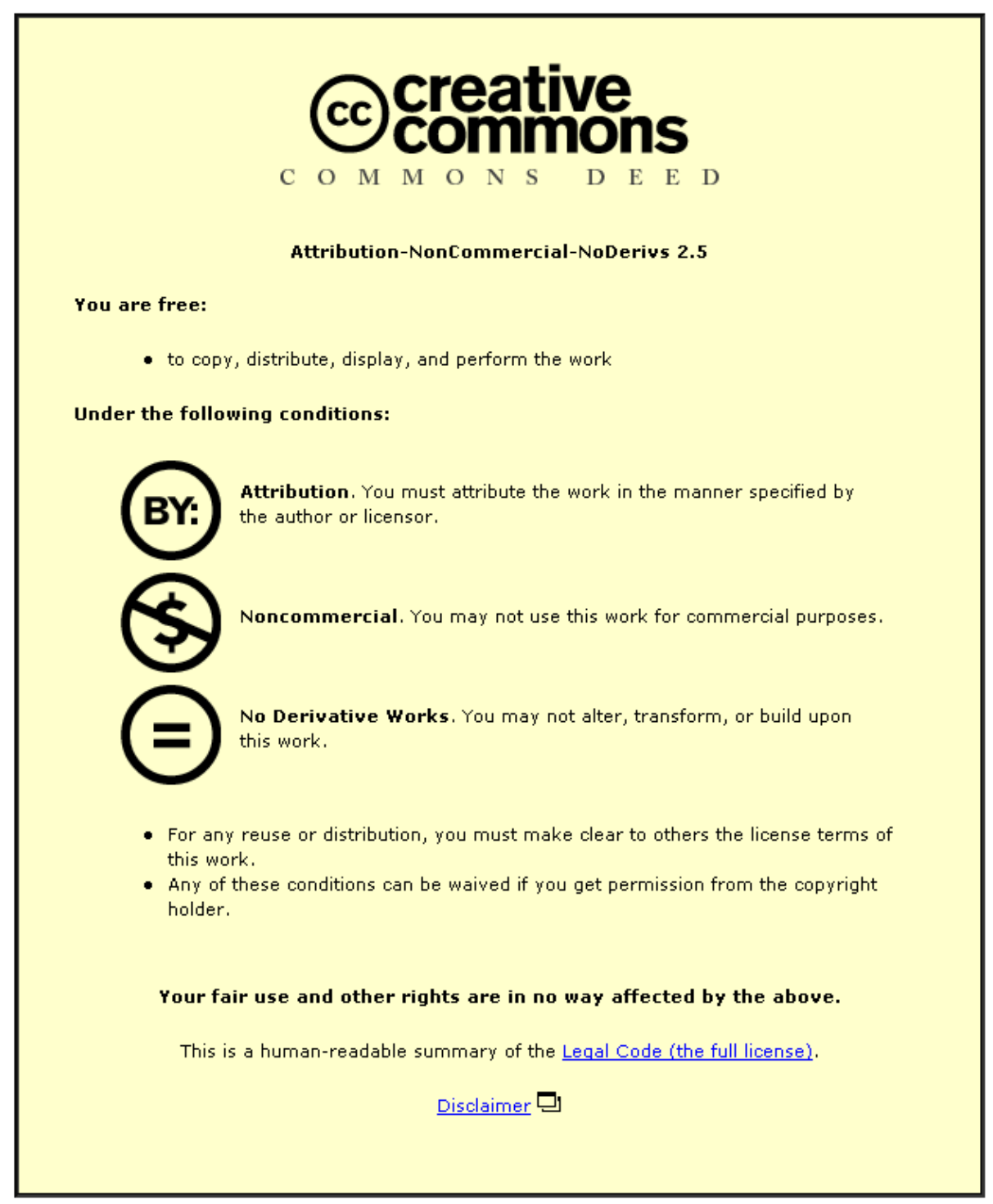

For the full text of this licence, please go to: http://creativecommons.org/licenses/by-nc-nd/2.5/ 


\title{
Case Based Reasoning Approach for Transaction Outcomes Prediction on Currency Markets
}

\author{
Xiaoming Wang, Martin D. Sykora, Robert Archer, David Parish, Helmut E. Bez \\ Electronic and Electrical Engineering \\ Research School of Informatics, Computer Science Department \\ Loughborough University, Loughborough, LE11 3TU, United Kingdom \\ E-mail: \{elxw,m.d.sykora,cora3,d.j.parish,h.e.bez\}@lboro.ac.uk \\ http://www. Iboro.ac.uk
}

\begin{abstract}
This paper presents a case based reasoning approach for making profit in the foreign exchange (forex) market with controlled risk using $k$ nearest neighbour ( $k N N)$ and improving on the results with neural networks (NNs) and a combination of both. Although many professionals have proven that exchange rates can be forecast using neural networks for example, poor trading strategies and unpredictable market fluctuation can inevitably still result in substantial loss. As a result, the method proposed in this paper will focus on predicting the outcome of potential trades with fixed stop loss (ST) and take profit (TP) positions ${ }^{1}$, in terms of a win or loss. With the help of the Monte Carlo method, randomly generated trades together with different traditional technical indicators are fed into the models, resulting in a win or lose output. This is clearly a case based reasoning approach, in terms of searching similar past trade setups for selecting successful trades. There are several advantages over classical forecasting associated with such an approach, and the technique presented in this paper brings a novel perspective to problem of exchange trades predictability. The strategies implemented have not been empirically investigated with such wide a range of time granularities as is done in this paper, in any to the authors known academic literature. The profitability of this approach is back-tested at the end of this paper and highly encouraging results are reported.
\end{abstract}

\section{INTRODUCTION}

The currency market as a whole is referred to as forex (foreign exchange). It's uniqueness is in its liquidity and trading volume. The forex market is the largest financial market in the world, with estimated daily trades exceeding a total of one trillion dollars. Virtually all international export and import is highly dependent on exchange rates. Currency markets are significant and London itself is the largest centre for currency trading in the world [4]. The GBP as a currency hence plays an important role in world currency trading and is focus of investigation in this study. Due to the tremendous scale of the market, it is often considered to follow an unpredictable random walk model [2], and be a zero-sum game in the long term [31]. We show that transactions that are likely to be successful in accumulating profits, even thought with high variability, can be predicted better than random and indeed quite consistently.

${ }^{1}$ A stop-loss and take-profit order are both orders which get executed when a particular price level is reached, one is used to limit losses, the other take profits, respectively.
The rest of this paper is organized as follows: in section I, background and novelty is discussed, section II presents our prediction system, in section III, the architecture of the model will be given, with results being demonstrated in section IV, followed by conclusions drawn and further work highlighted in section $\mathrm{V}$.

\section{A. EMH, Randomness and Predictability}

Leading on from assumption of random walk as a model for financial timeseries, the concept of EMH was first proposed by Fama in the 1960s [11]. Partly inspired by previous work in economics [2], [35], [36], he suggested that markets are information efficient. That is, agents taking part in a market have equally access to the same information, and as new information affecting a market comes out this information is counted into the market instantly, which leaves no room for using this information to make a profit. According to Fama [11] [25] there are three main forms of efficiency, weak form, semi strong form and strong form efficiency. The weak form efficiency is of such efficiency degree where excess returns cannot be made by using historical prices or other historical financial variables to make profits. In other words investment strategies using forecasts made from historical prices will not systematically outperform a buy-and-hold strategy ${ }^{2}$. Semi strong form efficiency proclaims that making use of strategies that integrate current publicly available fundamental information $^{3}$ and historical price information will not systematically outperform a buy-and-hold strategy. Even more radically in the strong form efficiency no one can earn any excess returns, as all information public and private is reflected in the share price, so even insider information will not be profitable. This has been strongly criticised and opposed by many professional traders who claim to have successfully outperformed markets to an extent not justifiable by pure chance [37], [38], [39], [8], [21]. In particular the whole field of equity analysis,

\footnotetext{
${ }^{2}$ Buy-and-hold strategy, is a simple market strategy, where assets are bought and held for the whole period in question. It is basically a benchmark that corresponds to underlying market growth.

${ }^{3}$ Fundamental information are represented in company financial statements and are generally hard facts about the current state and health of the company, such as turnover, assets, debt and profits.
} 
based on Technical Analysis [28] would be somewhat futile even if only weak form efficiency would hold. In practice we can imagine degree of efficiency to be on a continuous line, with any arbitrary efficiency degree possible, where the three efficiency forms simply represent three points on this continuous line. Indeed there are numerous academic critics of EMH [23], [43], [32], [17], [13], [34], to name a few. In 2004 Andrew Lo of MIT [22] put forward the Adaptive Market Hypothesis (AMH). The hypothesis proposes that instead of perfect and rational trading agents, the market participants adapt to changing markets, information, etc., in such a way as to lead to market efficiency. In the meantime until this efficiency is reached, there may well be exploitable excess returns on the markets.

It was found by authors of this paper that trade outcomes can be predicted with better than random accuracy. We believe the impact of our empirical work forms another case of support in favour of $\mathrm{AMH}$, in respect to the potential of efficiency exploitation in currency markets. This in relation to the GBP/USD exchange rate.

Indeed, Yao et al. have proposed an overview of forex technical forecasting [45], and Kamruzzaman et al. have shown that support vector machines (SVMs) and NNs could be used for predicting foreign currency exchange rates, respectively [18] [19].

\section{B. Standard approaches to Prediction}

Predicting currency-markets has always been one of greatest challenges in the financial domain. Much work was done on modelling and pattern searching time-series [10], [7], [47]. A time-series $Y=\left\{y_{1}, y_{2} \ldots y_{n}\right\}$ is a sequence of real or integer values in successive order, occurring at uniform intervals freq $=\{$ minutes, days, weeks, years, ... $\}$, where $n$ is the total number of values in the series. In plain terms, timeseries prediction refers to the process which tries to estimate the values of $y_{n+h}$, where $h$ is the forecast horizon. This is a regression problem, however it is not as important to predict real values as it is important to predict direction of future moves Leung et. al [20], [15] and hence the problem is sometimes approached as a classification task. This has its own advantages [16], [47], where the features are commonly some kind of preprocessed price or return delay-vector, and the class is a binned value, often these are represented by some fuzzy variables, such as large up move, up move, no move, down move, large down move see [41]. So now, given a series of prices of the form $y_{t-m} \ldots y_{t}$ we try to predict which of the $\left(B_{1}, \ldots, B_{L}\right) L$ bands, the data point $y_{t+h}$ will lie in rather than predicting $y_{t+h}$ itself. However, predicted exchange rate $y_{t+h}$ normally has a fixed forecast horizon, $h$. This makes it hard to utilise in the real mark with limited funds, especially trading with leverage ${ }^{4}$. Since we do not know how the market fluctuates within the period between $y_{t}$ and $y_{t+h}$, we cannot anticipate the magnitude of risk during the period.

\footnotetext{
${ }^{4}$ Levarage (or gearing) involves the borrowing of funds to increase the effect any moves have on investments.
}

Furthermore, just a few or even single large forecasting error may cause the investor to go bankrupt. Our work addresses this problem.

\section{Case Based Reasoning approach}

Instead of predicting timeseries themselves, we assert that it might be beneficial to develop trading strategies in terms of forecasting trade outcomes rather than future timeseries points. In other words, given a corpus of historical trades, where the initial conditions for the trade and the trade outcome (in terms of $P \& L^{5}$ ) are known, we seek to evaluate current trading opportunities against past transactions in the corpus to find profitable trades. This is a top down approach to prediction, and as such is a text book example of case based reasoning. A k nearest neighbour $(\mathrm{kNN})$ classifier [9] has therefore been used on a corpus of over 3 years GBP/USD exchange rate, monte carlo generated, transactions. There are approximately 2000 randomly generated transactions per year, hence around 6000 transaction instances are available.

As we are working on a per-order basis, $y$ is not taken into consideration. The orders we predicted as win or loss will occur somewhere in the future. To contrast with the standard prediction methods, the exchange rate $y$, between $t$ and $t+h$ is now constrained within a fixed range. This solution gives a fixed risk or profit per order, which is beneficial in practice in terms of managing trading margins and when considering transaction costs.

\section{OUR Prediction System}

Leverage is widely used by speculators in the liquidity markets, which leads to amplified profit, but simultaneously, amplified risk. Consequently, stop loss (SL) and take profit (TP) positions are commonly used in trading by investors with the intention of limiting loss and locking in profits. Using the techniques mentioned, potential profit orders may be closed by the volatility of the market, and a single large forecasting error or fluctuation could cause bankruptcy if SL and TP positions are not set. Moreover, compared to fluctuation, the errors of rate forecasting are still considerably high, which make forecast rate-based trading strategies difficult to use successfully. Some academics have looked at stop-loss orders and how they affect risk distributions [12], [46], [29] however in this paper we do not intend to join this debate instead we are purely interested into generating set cases of profitable or lossy transactions. In our work, trades with fixed SL and TP positions are used for controlling risk, making this model more feasible in practice when trading with limited funds. A useful side effect of this is that we do not have to worry about time frames of transactions as these are determined in terms of TP and SL positions.

As a base for our predictions we are going to use Technical Indicators. There is increasingly more evidence of the benefit of using such information in trading and prediction systems, for example price momentum and patterns in various assets

${ }^{5}$ Profit and Loss 
have been shown to exist with profitability value [3], [6], [5], [40], [30]. This information is widely used by trading professionals [27], [28], [24]. Finally the availability of price from which these indicators are calculated are widely accessible at multiple granularities with many data providers and brokers.

\section{A. The Forecasting Models}

Trading strategies were implemented using five forecasting methods. We used a $\mathrm{kNN}$ model to search the past training sample cases to make forecasts. We found that better results were obtained with $\mathrm{kNN}$ when the neighbourhood parameter $k$ was equal to 10 . This model is intuitive in the sense that out of all past profitable or lossy transaction cases, the most similar trade set-ups, based on 135 features (described later in subsection III-A) are selected, from these, the most likely trade outcome can be extrapolated. The number of features is large and features have different importance in varying market periods, it therefore makes sense to remove and only keep most useful features. We postulate that feature removal should improve prediction accuracy. We hence augmented the $\mathrm{kNN}$ with a greedy best features search so that the model is built based on training samples with different feature sets tested on validation set using cross validation. The model with greatest accuracy is selected, and finally tested on unseen testing samples.

Neural Networks have been reported to produce good results in financial forecasting [1], [33], [42], [26]. It was therefore anticipated that an $\mathrm{NN}$ model might improve performance over $\mathrm{kNN}$ method. The NN used in this paper is a multi-layer perceptron provided by WEKA[44]. The parameters are set to default, which have (attributes + classes)/2 hidden layers, a 0.3 learning rate, 0.2 momentum and 500 epochs training time.

Finally a simple vote based combined method, which combines both $\mathrm{kNN}$ with feature selection and $\mathrm{NN}$ with feature selection predictions has been built. Whenever both methods agree on the same extrapolated class, the Combo method makes a prediction. However, whenever these dissagree no prediction and hence no trade is made. This means the combined model will trade somewhat less frequently however with better accuracy, which is desired.

\section{EXPERIMENTAL DESIGN}

The goal of our experiment is to predict whether we should buy into or sell GBP/USD currency pair. We also evaluated success of these trade outcome based forecasts on real data. Accuracy and achieved profits were investigated on strictly unseen datasets. Two trading strategies were run, under each strategy five forecasting models were trained, validated and tested. Namely, k Nearest Neighbour, Neural Network and their variations, these were described in subsection II-A. The entire dataset was split into training, validation and unseen test data, using a sliding window approach, discussed in subsection III-B.
TABLE I

TECHNICAL INDICATORS USED AS FEATURES IN THE FEATURE SET

\begin{tabular}{|c|c|}
\hline Last Change \% & $\begin{array}{l}\text { Relative change within last data point } \\
\text { (close rate - open rate) / open rate }\end{array}$ \\
\hline SMA (5) \% & $\begin{array}{l}\text { Relative distance between close rate of last data point } \\
\text { and } 5 \text { periods Simple Moving Average } \\
\text { (close rate - SMA 5) / close rate }\end{array}$ \\
\hline SMA (10) \% & $\begin{array}{l}\text { Relative distance between close rate of last data point } \\
\text { and } 10 \text { periods Simple Moving Average } \\
\text { (close rate - SMA 10) / close rate }\end{array}$ \\
\hline SMA $(20) \%$ & $\begin{array}{l}\text { Relative distance between close rate of last data point } \\
\text { and } 20 \text { periods Simple Moving Average } \\
\text { (close rate - SMA 20) / close rate }\end{array}$ \\
\hline SMA (60) \% & $\begin{array}{l}\text { Relative distance between close rate of last data point } \\
\text { and } 60 \text { periods Simple Moving Average } \\
\text { (close rate - SMA 60) / close rate }\end{array}$ \\
\hline SMA (120) \% & $\begin{array}{l}\text { Relative distance between close rate of last data point } \\
\text { and } 120 \text { periods Simple Moving Average } \\
\text { (close rate - SMA 120) / close rate }\end{array}$ \\
\hline RSI (3) & Relative Strength Index of 3 periods \\
\hline RSI (13) & Relative Strength Index of 13 periods \\
\hline MACD (12 26) & $\begin{array}{l}\text { Moving Average Convergence / Divergence in } 12 \\
\text { and } 26 \text { periods }\end{array}$ \\
\hline $\begin{array}{l}\text { MACD } \\
\text { Signal (9) }\end{array}$ & Exponential moving average of MACD in 9 periods \\
\hline ADX (14) & Average Directional Index in 14 periods \\
\hline $\begin{array}{l}\text { ADX } \\
\text { DI+ (14) }\end{array}$ & Positive Directional Indicator in 14 periods \\
\hline $\begin{array}{l}\text { ADX } \\
\text { DI- (14) }\end{array}$ & Negative Directional Indicator in 14 periods \\
\hline $\begin{array}{l}\text { Bollinger } \\
\text { Upper Band } \\
\text { Distance } \\
\left(\begin{array}{ll}20 & 2\end{array}\right) \%\end{array}$ & $\begin{array}{l}\text { Relative distance between close rate of last data point } \\
\text { and } 20 \text { periods Bollinger band upper track with } 2 \\
\text { periods of standard deviation } \\
\text { (close rate - Bollinger band upper) / close rate }\end{array}$ \\
\hline $\begin{array}{l}\text { Bollinger } \\
\text { Lower Band } \\
\text { Distance } \\
\left(\begin{array}{lll}20 & 2\end{array}\right) \%\end{array}$ & $\begin{array}{l}\text { Relative distance between close rate of last data point } \\
\text { and } 20 \text { periods Bollinger band lower track with } 2 \\
\text { periods of standard deviation } \\
\text { (close rate - Bollinger band lower) / close rate }\end{array}$ \\
\hline
\end{tabular}

\section{A. Input Data}

For our experiments we selected 15 quarters of historical GBP/USD exchange rates. The data set considered covers period from 1st April 2005 to 31st December 2008 and is obtained through MetaTrader 4, an automated trading system platform. The MetaTrader 4 system is used to generate approximately 500 long positions on GBP/USD per quarter at random times with fixed SL and TP.

As we are working on a per-order basis, the features are different indicators at the time of order sent, and the output is whether this order is a monetary loss or monetary gain assuming only long positions. The indicators we used are calculated based on the price changes within 9 different time granularities; 1 min, 5 mins, 15 mins, 30 mins, 1 hour, 4 hours, 1 day, 1 week and 1 month. For each period, the following indicators shown in table I are computed to form the feature set of our data tuples, of which there is 135 in total. These features together with the output class form our data tuples for our classification problem.

\section{B. Training, Validation and Testing Procedure}

The original data is parsed by a sliding window so that 10 training data sets and 10 testing data sets are derived. For each training set, there are 4 yearly quarters of data, around 2000 


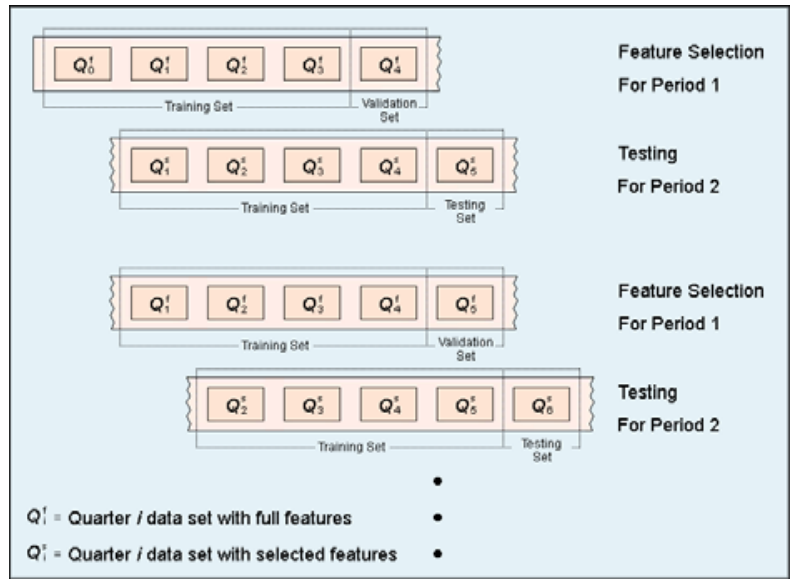

Fig. 1. Sliding window, training, testing and validation datasets

trades, and each testing set contains 1 quarter data, around 500 trades. All the training data of the classifier should be balanced, in order to keep equal amount of loss and win trades [14]. The instance set has been balanced by method of random undersampling. Moreover, we ensure all the trades in the training data are closed within the training data period. In other words, the trades we used to train the model cannot fall into time periods of validation and test datasets.

For the method of feature selection, additional validation data set has been used. This dataset was the most recent quarter prior to the unseen test data. Once model was validated, final model was trained on the 4 quarter sliding window, including the validation dataset, which was incorporated into the training dataset. The process is illustrated in Fig. 1.

For period 1, the $Q_{0}-Q_{1}$ quarter data with all features are used to train the $\mathrm{kNN}$ and $\mathrm{NN}$ models. Greedy searching method based on the validation data $Q_{4}$, is used to select the features from both models. Then, the $Q_{1}-Q_{4}$ data only with selected features get trained, and the test is performed against the $Q_{5}$ data. For period 2, the process is moved forward one quarter. Where $Q_{1}-Q_{4}$ data is used as training data for selecting features based on the $Q_{5}$, and $Q_{2}-Q_{5}$ data is used to perform the testing against $Q_{6}$. Totally, 10 periods of testing are gone through.

\section{RESUlts}

The trading data set is generated with 2 different TP and SL positions, the first one is at $0.5 \%$ and second one is at $2 \%$. For each data set, 5 forecasting methods have been used. In table II we can see the results of a $0.5 \%$ strategy. A random predictor would on average output 50\% accuracy level. As it can be appreciated from table II, the average accuracies for all models are actually above $50 \%$. However, these are not significantly better than random, as the $0.5 \%$ trades tend to be more influenced by noise, i.e. small random fluctuations on the exchange rate. In other words, trades are closed too frequently on small hard to predict moves. Further we can see from columns, Sample no. and Combine no. (Combine no. represents the actual number of trades on which both models
TABLE II

RESULTS FOR A $0.5 \%$ TRADING STRATEGY

\begin{tabular}{|c|c|c|c|c|c|c|c|}
\hline Periods & $\begin{array}{c}\text { Smpl } \\
\text { No. }\end{array}$ & $\begin{array}{c}\text { kNN } \\
\text { Acc. } \\
(\%)\end{array}$ & $\begin{array}{c}\text { NN } \\
\text { Acc. } \\
(\%)\end{array}$ & $\begin{array}{c}\text { kNN. } \\
\text { Acc. } \\
(\%)\end{array}$ & $\begin{array}{c}\text { FN.S. } \\
\text { Acc. } \\
(\%)\end{array}$ & $\begin{array}{c}\text { Comb. } \\
\text { Smpl } \\
\text { No. }\end{array}$ & $\begin{array}{c}\text { Comb. } \\
\text { Acc. } \\
(\%)\end{array}$ \\
\hline 06 Q3 & 651 & 51.46 & 51.15 & 51.00 & 45.47 & 209 & 44.50 \\
\hline 06 Q4 & 579 & 57.34 & 46.63 & 45.94 & 58.20 & 444 & 52.70 \\
\hline 07 Q1 & 532 & 57.89 & 63.91 & 62.22 & 62.78 & 249 & 76.71 \\
\hline 07 Q & 487 & 57.29 & 54.41 & 57.49 & 60.37 & 133 & 82.71 \\
\hline 07 Q3 & 545 & 53.21 & 51.93 & 47.16 & 51.93 & 285 & 49.12 \\
\hline 07 Q & 568 & 54.75 & 45.25 & 45.42 & 46.83 & 308 & 42.86 \\
\hline 08 Q1 & 564 & 54.26 & 52.84 & 49.47 & 50.35 & 363 & 49.86 \\
\hline 08 Q2 & 534 & 52.81 & 55.62 & 54.68 & 50.94 & 306 & 54.90 \\
\hline 08 Q3 & 576 & 47.05 & 47.57 & 45.49 & 51.22 & 163 & 44.17 \\
\hline 08 Q4 & 529 & 51.80 & 50.09 & 55.01 & 42.16 & 129 & 44.19 \\
\hline $\begin{array}{c}\text { Total } \\
\text { Smpl } \\
\text { No. }\end{array}$ & 5565 & & & & & 2589 & \\
\hline $\begin{array}{c}\text { Average } \\
\text { Acc. } \\
\text { (\%) }\end{array}$ & & 53.79 & 51.94 & 51.39 & 52.02 & & 54.00 \\
\hline $\begin{array}{c}\text { Acc. } \\
\text { Std. } \\
\text { Dev. }\end{array}$ & & 3.32 & 5.37 & 5.78 & 6.63 & & 14.10 \\
\hline $\begin{array}{c}\text { Overall } \\
\text { Acc. } \\
\text { (\%) }\end{array}$ & & 53.69 & 51.79 & 51.18 & 51.82 & & 53.23 \\
\hline
\end{tabular}

TABLE III

RESULTS FOR A BUY AND HOLD STRATEGY

\begin{tabular}{|c|c|c|c|c|}
\hline Periods & open & close & $\%$ & abs (\%) \\
\hline 06 Q3 & 1.85 & 1.87 & 1.34 & 1.34 \\
\hline 06 Q4 & 1.87 & 1.96 & 4.49 & 4.49 \\
\hline 07 Q1 & 1.96 & 1.97 & 0.34 & 0.34 \\
\hline 07 Q2 & 1.97 & 2.01 & 1.99 & 1.99 \\
\hline 07 Q3 & 2.01 & 2.05 & 1.82 & 1.82 \\
\hline 07 Q4 & 2.05 & 1.98 & -2.98 & 2.98 \\
\hline 08 Q1 & 1.99 & 1.98 & -0.18 & 0.18 \\
\hline 08 Q2 & 1.98 & 1.99 & 0.49 & 0.49 \\
\hline 08 Q3 & 1.99 & 1.78 & -10.53 & 10.53 \\
\hline 08 Q4 & 1.78 & 1.46 & -18.29 & 18.29 \\
\hline \hline Avg. &. &. & -2.15 & 4.24 \\
\hline
\end{tabular}

have agreed on) that there seems to be much disagreement between $\mathrm{NN}$ and $\mathrm{kNN}$. In comparison Combine no. in table IV is significantly larger, which points to the fact that models in a $2 \%$ strategy tend to agree more often on the prevailing trend / trade outcome, which supports the assumption that $2 \%$ trades tend to be more predictable.

From the results of $2 \%$ strategy, the combine model attains the highest accuracy average, $63.76 \%$ among 10 quarters, and $61.98 \%$ accuracy based on total samples, the standard deviation of this method is acceptable compared with other models. Moreover, only one quarter of accuracy is below $50 \%$. The results also support our assumptions that, feature selection can improve accuracy and $\mathrm{NN}$ performs better than $\mathrm{KNN}$. There is one line missing at "07 Q1" for those methods that use feature selection. After investigation of the relevant dataset, it was found that this was caused by there only being one sample of $2 \%$ loss trade, for long position, existing in the validation data set. As a result, the greedy forward search cannot find any feature set for improving classification. 
TABLE IV

RESULTS FOR A $2.0 \%$ TRADING STRATEGY

\begin{tabular}{|c|c|c|c|c|c|c|c|}
\hline Periods & $\begin{array}{c}\text { Smpl } \\
\text { No. }\end{array}$ & $\begin{array}{c}\text { kNN } \\
\text { Acc. } \\
(\%)\end{array}$ & $\begin{array}{c}\text { NN } \\
\text { Acc. } \\
(\%)\end{array}$ & $\begin{array}{c}\text { kNN } \\
\text { F.S. } \\
\text { Acc. } \\
(\%)\end{array}$ & $\begin{array}{c}\text { NN.S. } \\
\text { Acc. } \\
(\%)\end{array}$ & $\begin{array}{c}\text { Comb. } \\
\text { Smpl } \\
\text { No. }\end{array}$ & $\begin{array}{c}\text { Comb. } \\
\text { Acc. } \\
(\%)\end{array}$ \\
\hline 06 Q3 & 651 & 40.09 & 43.78 & 46.54 & 36.10 & 583 & 40.31 \\
\hline 06 Q4 & 579 & 46.46 & 33.85 & 81.17 & 66.15 & 362 & 87.85 \\
\hline 07 Q1 & 532 & 60.55 & 79.89 & n/a & n/a & n/a & n/a \\
\hline 07 Q2 & 487 & 36.96 & 59.14 & 47.02 & 66.12 & 328 & 59.76 \\
\hline 07 Q3 & 545 & 81.10 & 74.68 & 79.82 & 75.41 & 461 & 82.65 \\
\hline 07 Q4 & 568 & 50.35 & 51.41 & 58.45 & 52.46 & 508 & 56.1 \\
\hline 08 Q1 & 564 & 51.77 & 54.61 & 48.05 & 59.93 & 355 & 56.34 \\
\hline 08 Q2 & 534 & 62.36 & 62.17 & 67.98 & 62.36 & 468 & 67.31 \\
\hline 08 Q3 & 576 & 53.30 & 58.33 & 55.38 & 53.82 & 533 & 54.97 \\
\hline 08 Q4 & 529 & 40.83 & 66.92 & 40.64 & 64.65 & 105 & 68.57 \\
\hline $\begin{array}{c}\text { Total } \\
\text { Smpl } \\
\text { No. }\end{array}$ & 5565 & & & & & 3703 & \\
\hline $\begin{array}{c}\text { Average } \\
\text { Acc. } \\
\text { (\%) }\end{array}$ & & 52.38 & 58.48 & 58.34 & 59.67 & & 63.76 \\
\hline $\begin{array}{c}\text { Acc. } \\
\text { Std. } \\
\text { Dev. }\end{array}$ & & 13.14 & 13.72 & 14.88 & 11.21 & & 13.86 \\
\hline $\begin{array}{c}\text { Overall } \\
\text { Acc. } \\
\text { (\%) }\end{array}$ & & 52.26 & 57.92 & 58.36 & 59.05 & & 61.98 \\
\hline
\end{tabular}

For more confirmation on our results we also decided to compare our model to a commonly used benchmark strategy. For the simplest buy and hold trading strategy, if the investor always goes into long positions, they would on average actually achieve a loss of $2.15 \%$ over the 10 quarter test data period ${ }^{6}$. Assuming the investors are clever enough to utilise every movement, they can on average obtain a profit of $4.24 \%$. This is illustrated in table III. Compared with our best performing model, which has a hit rate of $61 \%$, and a $2 \%$ profit or loss for each trade, the average profit per trade is given by

$$
P=(61 \%-(1-61 \%)) * 2 \%=0.44 \%
$$

This means, it takes 10 trades per quarter to achieve same profit as an "unrealistically lucky" trader with a buy and hold strategy, who would always get the market direction right.

\section{CONCLUSION AND FurTher WORK}

We presented a case based reasoning approach for making profit in the foreign exchange market on the GBP/USD currency pair using $\mathrm{k}$ nearest neighbour $(\mathrm{kNN})$, improving on the results with neural networks (NNs), feature selection and a combination of both. Results for two different trading strategies are presented. We argue that forecasting the actual time series bares more risk and is less useful in practice than our technique, where we know that during a given forecast horizon, exchange rate is constrained and will not exceed an upper / lower boundary. The results clearly show that using $2 \%$ trade strategy, on average we predict exchange rate direction with $61 \%$ accuracy, using best predictor.

${ }^{6}$ This performance is due to a negative market trend, however for a long term period average market return would tend towards $0 \%$.
We effectively built a slot machine giving us a $22 \%^{7}$ edge on the GBP/USD currency pair. Over the long term such a system is capable of yielding significant profits, even when transaction costs are considered. However, due to large standard deviation (see tables II and IV, second row from bottom), in short term, there is risk of consecutive unlucky periods. Good performance of the system can also be attributed to the dynamic selection (every quarter), of indicators and time granularities on the most recent exchange rate data, prior to the unseen testing period.

There are number of improvements that could be made to the system and future work we plan to undertake. It would be interesting to try our approach on different currencies, as well as other asset markets, such as commodities, stocks and mutual funds. Further it might be of value to investigate the forecast potential of some related macroeconomic time-series, such as interest rates, inflation rates, and others. Also an investigation of different SL \& TP levels, where these are set assymetrically could be undertaken in future.

\section{REFERENCES}

[1] E. M. Azoff. Neural Network Time Series Forecasting of Financial Markets. John Wiley, 1994. ISBN: 0471943568.

[2] L. Bachelier. Thorie de la spculation. Annales Scientifiques de lcole Normale Suprieure, 3:21-86, 1900.

[3] W. Brock, J. Lakonishok, and B. LeBaron. Simple technical trading rules and the stochastic properties of stock returns. The Journal of Finance, 47:1731-1764, 1992.

[4] J. Burrell. The Complete Guide to Currency Trading \& Investing: How to Earn High Rates of Return Safely and Take Control of Your Investments. Atlantic Publishing Company, 2007.

[5] G. Caginalp and H. Laurent. The predictive power of price patterns. Applied Mathematical Finance, 5(3):181-205, 1998.

[6] L. K. C. CHAN, N. JEGADEESH, and J. LAKONISHO. Momentum strategies. Journal of Finance, 51:1681-1713, 1996.

[7] C. Chatfield. The Analysis of Time Series, an Introduction. 1996. ISBN 0-412-71640-2.

[8] M. W. Covel. The Complete TurtleTrader: The Legend, the Lessons, the Results. Collins, 2007.

[9] T. M. Cover and P. E. Hart. Nearest neighbor pattern classification. Institute of Electrical and Electronics Engineers Transactions on Information Theory, 13:21-27, 1967.

[10] S. A. DeLurgio. Forecasting Principles and Applications. 1998. ISBN 0-256-13433-2.

[11] E. Fama. Random walks in stock market prices. Financial Analysts Journal, 51, 1965.

[12] T. Foucault. Order flow composition and trading costs in a dynamic limit order market. Journal of Financial Markets, 2:99-134, 1999.

[13] A. Garliauskas. Neural network chaos and computational algorithms of forecast in finance. In 1999 IEEE International Conference on Systems, Man, and Cybernetics, 1999. IEEE SMC '99 Conference Proceedings., volume 2, pages 638 - 643, Tokyo, October 1999.

[14] B. Geapa, A. Bazzan, and M. Monard. Balancing training data for automated annotation of keywords: a case study. In Proceedings of the Second Brazilian Workshop on Bioinformatics 2003, 2003.

[15] T. Hellstrm. A random walk through the stock market. Master's thesis, Department of Computing Science, Ume University, Ume Sweden, December 1998. ISSN-0348-0542.

[16] T. Hellstrm and K. Holmstrm. Predicting the stock market. Technical report, 1998. published as Opuscula ISRN HEV-BIB-OP-26-SE, also available as Technical Report Series IMa-TOM-1997-07.

[17] D. Hsieh. Chaos and nonlinear dynamics: Application to financial markets. Journal of Finance, 46:1839-1877, 1991.

${ }^{7}$ Given by $(61 / 100)+(-1 *(39 / 100))$, assuming a $61 \%$ chance on average of correct outcome prediction. 
[18] J. Kamruzzaman and R. Sarker. Forecasting of currency exchange rates using ann: A case study. In In Proc. IEEE Intl. Conf. on Neur. Net. \& Sign. Process. (ICNNSP03), pages 793-797, China, 2003.

[19] J. Kamruzzaman, R. Sarker, and Ahmad. Svm based models for predicting foreign exchange rates. In In Proc. 3rd IEEE Intl. Conf. on Data Minind (ICDM'03), pages 557-560, Florida, USA, 2003.

[20] M. Leung, H. Daouk, and A. Chen. Forecasting stock indices: a comparison of classification and level estimation models. International Journal of Forecasting, 16(2):173-190, 2000.

[21] J. Livermore. How to Trade In Stocks. McGraw-Hill, 2006.

[22] A. Lo. The adaptive market hypothesis: Market efficiency from an evolutionary perspective. Journal of Portfolio Management, 30:15-29, 2004.

[23] A. Lo and A. Mackinley. Stock market prices do not follow random walks: Evidence from a simple specification test. NBER Working Paper, 1989.

[24] A. Lo, H. Mamaysky, and J. Wang. Foundations of technical analysis: Computational algorithms, statistical inference, and empirical implementation. The Journal of Finance, 55(4):1705-1765, 2000.

[25] B. Malkiel. A Random Walk Down Wall Street: The Time-tested Strategy for Successful Investing. W. W. Norton, 1973.

[26] P. D. McNelis. Neural Networks in Finance: Gaining Predictive Edge in the Market. Academic Press, 2004. ISBN-10: 0124859674.

[27] J. J. Murphy. The Visual Investor: How to Spot Market Trends. Wiley, 1996.

[28] J. J. Murphy. Technical Analysis of the Financial Markets: A Comprehensive Guide to Trading Methods and Applications. Prentice Hall, 1999.

[29] C. L. Osler. Stop-loss orders and price cascades in currency markets. Journal of International Money and Finance, 24:219-241, 2005.

[30] M.-S. Pan, K. Liano, and G.-C. Huang. Industry momentum strategies and autocorrelations in stock returns. Journal of Empirical Finance, 11(2):185-202, March 2004.

[31] E. E. Peters. Chaos and Order in the Capital markets: A New View of Cycles, Prices, and Market Volatility. New York: Wiley, 1991.

[32] E. E. Peters. Fractal Market Analysis: Applying Chaos Theory to Investment and Economics. John Wiley and Sons, 1994.

[33] A.-P. Refenes. Neural Networks in the Capital Markets. John Wiley, March 1995. ISBN: 0471943649.

[34] M. Rubinstein. Rational markets: Yes or no? the affirmative case. Financial Analysts Journal, 57:15-29, 2001.

[35] P. Samuelson. Brownian motion in the stock market. 1955.

[36] P. Samuelson. Proof that properly anticipated prices fluctuate randomly. Industrial Management Review, 6:4149, 1965.

[37] J. D. Schwager. Market Wizards: Interviews with Top Traders. Marketplace Books, 2006.

[38] J. D. Schwager. The New Market Wizards: Conversations with America's Top Traders. Marketplace Books, 2008.

[39] J. D. Schwager. Stock Market Wizards: Interviews with America's Top Stock Traders. Marketplace Books, 2008.

[40] R. Sullivan, A. Timmermann, and H. White. Data-snooping, technical trading rule performance, and the bootstrap. The Journal of Finance, 54:1647-1691, 1999.

[41] M. D. Sykora and S. Singh. Development of trading strategies based on risk-analysis of stocks. In IWAPR 2007 Conference Proceedings, 2007.

[42] J. G. Taylor, J. Shadbolt, C. Adcock, D. Attew, N. Burgess, N. Hazarika, S. Larsson, and N. Towers. Neural Networks and the Financial Markets: Predicting, Combining and Portfolio Optimisation. Springer, 2002. ISBN: 1-85233-531-9.

[43] G. P. Williams. Chaos Theory Tamed, volume 1. Joseph Henry Press, October 1997. ISBN-10: 0309063515.

[44] I. Witten and E. Frank. Data Mining: Practical Machine Learning Tools and Techniques. Morgan Kaufman, 2005. ISBN 0-120-88407-0.

[45] J. Yao and C. L. Tan. A case study on using neural networks to perform technical forecasting of forex. Neurocomputing, 34:79-98, 2000. Elsevier.

[46] S. yu Shen and A. M. Wang. On stop-loss strategies for stock investments. Applied Mathematics and Computation, 119:317-337, 2001.

[47] S. Zemke. Data Mining for Prediction. Financial Series Case. PhD thesis, The Royal Institute of Technology, Department of Computer and Systems Sciences, Sweden, 2003. 